\title{
Marília Garcia: para onde nos levam as hélices do poema?
}

Andréa Catrópa da Silva ${ }^{1}$

No ensaio "Poesia auto-móvel", Viviana Bosi analisa como a relação dos poetas contemporâneos com o ambiente urbano exacerbou as percepções do flâneur baudelairiano. Segundo a autora, o deslocamento via meios de transporte poderia simbolizar as experiências fugidias que são registradas pelo olhar lírico e partilhadas com os leitores, já que:

[...] o que, desde Aristóteles, especialmente designa o poético é sua qualidade de virada, reviravolta (trópos): transporte de um lugar (semântico que seja) para outro, a reconfigurar-lhe o sentido. Transformar a landscape em inscape (Hopkins), numa síntese mental, ou arabesco do real (Baudelaire), ou correlato objetivo (Eliot) é sua função de deslocamento (desvio para alguns; encontro e alumbramento para outros) também na poesia urbana hoje (Bosi, 2010, p. 141).

No texto, são analisados três poemas em que o sujeito lírico observa a cidade de dentro de seu automóvel. Um deles é de Ana Cristina Cesar (2013), poeta em cuja obra os meios de transporte proporcionam a instabilidade do deslocamento que, por vezes, respeita, por outras, contraria o desejo do coração. Ainda que examine poemas publicados em fins do século $\mathrm{XX}$, podemos considerar que o referido ensaio traga uma observação fronteiriça entre modernidade e pós-modernidade, que permita criar bases de comparação com as publicações de início do século XXI.

Aqui, nosso interesse específico recai sobre a poesia de Marília Garcia, que estreou na cena literária em 2007 com 20 poemas para seu walkman. Desde essa estreia, menções aos meios de transporte são uma constante em seus poemas. No entanto, diferentemente do que ocorre no corpus examinado por Viviana Bosi, na obra da poeta carioca ganham mais destaque os aviões, voos, aeroportos. Só para citar exemplos de versos que estão espalhados nesse primeiro livro: “o ziguezague do avião sempre que saíam juntos"; "não é o avião em

${ }^{1}$ Doutora em teoria literária e pós-doutoranda em design na Universidade Anhembi Morumbi, São Paulo, SP, Brasil. Đorcid.org/0000-0003-0185-8167. E-mail: andreacatropa@gmail.com 
rasante sobre"; "era a hora certa mas o avião girava em ângulo reto"; "o avião aterrando deixou tudo claro"; "pergunta a que horas sai seu voo"; "para Hong Kong num voo"; "dois voos na mesma cidade"; "a aeronave se desloca com".

Figuram nessa obra, portanto, deslocamentos e viagens que transcendem os limites locais, trazendo ao conjunto de poemas uma aura marcadamente cosmopolita. Não só o cenário de cada poema é diversificado, como também a nacionalidade das personagens que ali surgem é sortida, revelando um trânsito intenso de afetos e ideias que não se restringe à demarcação territorial dos países. São encontros, leituras, traduções - gérmens intelectuais e fraternos que brotam aqui e acolá, embaralhando o espaço e carregando os corpos em movimento com memórias que preenchem as descrições e narrativas compartilhadas com o leitor.

Le pays n'est pas la carte,

pensa bem, mas

se tivesse as ruas quadradas

teria ido a outro café, teria dito tudo de

outro modo e visto de

cima a cidade em vez de se

perder toda vez

na saída do metrô. não é desagradável

estar aqui, é apenas

demasiado real diz com cílios erguidos

procurando um mapa

II

não é o avião em rasante sobre

a água e nem o corpo

na janela semiaberta

vendo o desenho

dos carros embaixo - não comenta nada

porque prefere armar planos

em silêncio

(estaria sonhando

com colinas?)

III 


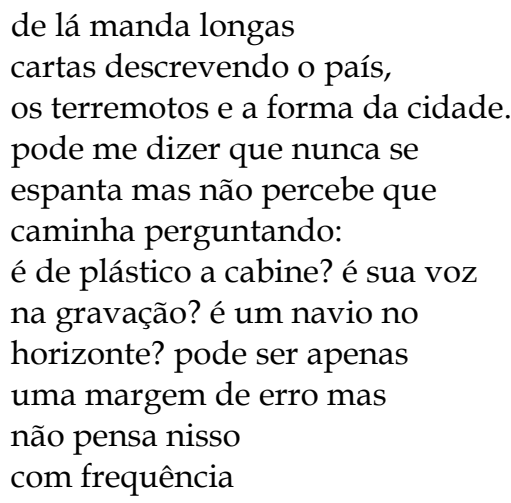

(pode ser apenas a janela

aberta que carrega os papéis) (Garcia, 2007, p. 31).

No entanto, como é perceptível no poema, há uma síntese que transforma o espaço em campo passível de abstração para melhor se acomodar à memória. Esse traço toma outro rumo no livro Teste de resistores (2014), em que a precisão de anotação do processo vale tanto quanto a composição poética do percurso. Em seu texto de abertura, notamos esse aspecto tateante, em busca de nitidez, já nos primeiros versos:

poderia começar de muitas formas

e esse começo poderia ser um movimento ainda sem direção

que vai se definindo

durante o trajeto

poderia começar situando o tempo e o espaço

contexto hoje é quarta-feira dia 27 de novembro

e estamos no $3^{\circ}$ andar do centro universitário maria antônia também faria uma pergunta

nesse caso com quem estou falando aqui hoje?

poderia começar contando que me mudei para são paulo

há exatos 3 meses

e que esse convite do maurício

foi como um gesto de

delicadeza e acolhida

pensando bem

poderia resumir

minha curta experiência nesta cidade 
com a palavra delicadeza (Garcia, 2016, p. 11).

O título do longo poema, que tem 29 páginas e está organizado em 24 seções, é Blind light. ${ }^{2} \mathrm{O}$ nome coincide com uma instalação do escultor inglês Antony Gormley, que é uma espécie de aquário gigante onde entram os visitantes e ficam imersos em uma nuvem espessa de neblina. Segundo o artista:

A arquitetura supostamente existe para ser o local da segurança e da certeza sobre onde você está. Ela deveria proteger você do clima, da escuridão, da incerteza. BLIND LIGHT abala tudo isso. Você adentra neste espaço que é como estar no topo de uma montanha ou no fundo do mar. É muito importante para mim que dentro dele você encontre o lado de fora. Além disso, imerso nesse terreno infinito, você literalmente se torna o sujeito da obra (Gormley, 2007, s.p., tradução nossa).

Podemos especular que, talvez, tanto a instalação de Gormley quanto a poesia de Marília Garcia sejam convites a uma percepção do entorno livre de automatismos, uma exploração do espaço que leva, ao mesmo tempo, a uma nova descoberta do eu. Assim, especialmente no caso de Teste de resistores, as referências geográficas que, pouco a pouco, vão ganhando forma, são determinantes para a construção da voz que fala no texto, deste ou daquele lugar, ou ainda, sobre determinados locais.

Traços das obras anteriores são perceptíveis no mais recente trabalho publicado por Marília Garcia, mas com diferenças no que diz respeito ao resultado obtido. Câmera lenta (2017) é a revelação de um percurso que busca testar os limites da linguagem poética, ao mesmo tempo que, ludicamente, convida o leitor a participar dessa aventura. O texto de abertura, "hola, spleen", opera como uma máquina do tempo que nos leva, junto com a voz do poema, ao instante em que ocorre uma leitura, como podemos verificar nesta estrofe:

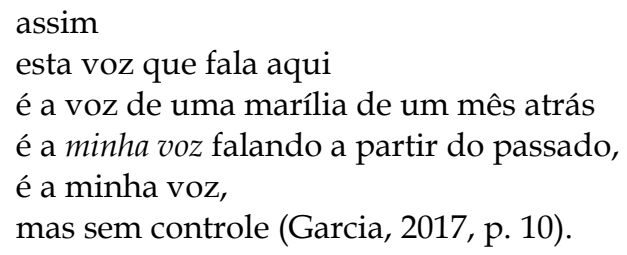

${ }^{2} \mathrm{O}$ tema será ainda tratado no poema "Um quadrado que cega", publicado em Câmera lenta (2017). 
Esses versos já nos permitem vislumbrar alguns questionamentos que se colocam em Câmera lenta desde seu início. Um deles é justamente a problematização da instituição do sujeito lírico que, sobretudo desde o simbolismo francês, foi sendo mais e mais apartado do sujeito biográfico. No entanto, as discussões acerca dessa relação problemática entre o "eu" que vive e o "eu" fixado no texto ganhou fôlego e novos desdobramentos ao longo do século XX, suavizando essa separação rígida entre vida e literatura. No Brasil, em meio à "geração mimeógrafo", o mote era convidar o leitor para uma experiência poética que se assemelhasse à anotação rápida do momento. Particularizando-se nesse contexto, destaca-se a obra de Ana Cristina Cesar (2013) - uma precursora dos desdobramentos poéticos realizados por Marília Garcia - cujos "híbridos de carta e diário que conectam a sua poesia à coloquialidade marginal dos anos 70, ao mesmo tempo, a particularizam" (Catrópa, 2015, p. 128).

Internacionalmente, o debate sobre as novas configurações possíveis para o sujeito lírico na poesia foi abordado com grande interesse pelo grupo Problématique et Analyse des Modernités Littéraires, cujas investigações resultaram num volume especial da coleção Modernités sobre o assunto (Rabaté, Sermet e Vadé, 1996). Também no mesmo ano surge o livro Figures du sujet lyrique (2001), organizado por Dominique Rabaté e com ensaios de diversos autores que se debruçaram sobre o assunto, como Michel Collot, Dominique Combe e Jean-Michel Malpoix. Este último é o principal divulgador e pesquisador do conceito de lirismo crítico, que propõe uma "poética do sujeito relacionada à fenomenologia e centrada em um sujeito que fala da vida e, consequentemente, do mundo" (Milaneze, 2014, p. 2).

Questionar a natureza do sujeito lírico é atentar para a lacuna entre esse "eu" lírico e o "eu" biográfico... Eu defini em outro lugar esse "eu" lírico como "quarta pessoa singular". Um potencial eu, um eu em potência, um hiper ou infra sujeito, uma criatura complexa com traços aleatórios, de tal forma que a abordagem "clássica" da autobiografia não será suficiente para reunir suas características [...]. Ele é o porta-voz de uma pluralidade (Maulpoix, 2001, s.p., tradução nossa).

É, porém, em outra corrente que também participou das discussões sobre os impasses em torno da voz lírica na França a partir da segunda metade do século XX que encontraremos alguns dos principais 
interlocutores de Marília Garcia no plano da poesia internacional em língua francesa, como Nathalie Quintaine e Emmanuel Hocquard. Ambos foram traduzidos pela poeta e a obra deste último foi objeto de investigação de sua tese de doutorado (Garcia, 2010).

Nessa corrente identificada a uma poesia literal, há a busca de referências a locais e fatos concretos, que se mesclam a procedimentos criativos advindos de outras linguagens artísticas como o cinema e a fotografia - para driblar a recorrência de descrições típicas da linguagem poética. Hocquard afirma que "a literalidade é vertiginosa como esse tipo de tautologia com duplo gatilho que produz" (Rabaté, Sermet e Vade, 1996, p. 285). Ela remete a algo que já foi dito ou ocorrido, fazendo com que a escrita seja, simultaneamente à sua origem, também uma cópia.

Em relação ao sujeito lírico, este pode surgir, por vezes, sem o peso da dimensão autobiográfica, como um lugar vazio cuja enunciação deve ser preenchida pelo outro que a lê. Nas palavras de Michel Deguy (Rabaté, Sermet, Vade, 1996, p. 295-296, tradução nossa), "escrever - não é um mistério. Pensar é falar; falar é escrever". Assim, para o poeta francês, não haveria nada por trás das palavras, apenas diante delas. E um dos papéis da poesia seria figurar as operações do pensamento e encontrar na matéria um correlato do elemento sensível, uma imagem capaz de demonstrar os esquematismos da capacidade de pensar.

Se observarmos atentamente, quase todos os poemas do livro Câmera lenta são construídos em primeira pessoa. Isso não apaga, porém, o mundo exterior a esse "eu" que se define, frequentemente, em contraste com um outro ("você", "ele", "ela"). A relação conflituosa com a alteridade pode ser evocada em uma memória que emerge do passado, mas pode também surgir no presente, em estrutura dialógica:

não se perde alguém por duas

vezes, era o que achava

mas a essa altura chego no mesmo terminal

duas semanas depois e a cena se

repete.

- você está tendo um problema

de realidade, ele cochichou.

- qual é o desastre desta vez? (Garcia, 2017, p. 20) 
O trecho acima, tirado de "pelos grandes bulevares", exemplifica bem a construção de uma voz que se insere no mundo a partir de configuração diversa daquela proposta pela poesia concreta, que tendia a relacionar a intensidade subjetiva de um poema com falta de objetividade. Se o "eu" nos textos de Marília Garcia não se perde em abstrações, sua concretude advém da própria inserção em uma cena que depende de outras "personagens", bem como do "cenário", para se projetar. A voz do poema não se volta apenas para o leitor, antes, constrói-se na iminência da ação que se desenrola nos versos. Sobre esse processo de constituição peculiar da arte poética, Dominique Combe afirma:

Longe de exprimir-se como um sujeito já constituído que o poema representaria ou exprimiria, o sujeito lírico está em permanente constituição, em uma gênese constantemente renovada pelo poema, fora do qual ele não existe. $O$ sujeito lírico se cria no e pelo poema, que tem valor performativo (Combe, 2010, p. 128).

Quando enfocamos especificamente a literatura nacional, podemos afirmar que as experimentações encontradas nesse volume não privilegiam a secura e a precisão formal, nem a brevidade de alguns poemas encontrados em Esses Poetas - Uma antologia dos anos 90, organizada por Heloísa Buarque de Hollanda (1998). Talvez porque naquele fim de século, tanto o formalismo vanguardista quanto a "estética do desleixo" da poesia marginal carioca fossem observados com desconfiança, e poetas como Claudia RoquettePinto, Alberto Martins e Carlito Azevedo estivessem abrindo caminhos para propostas que obedecessem a uma gama de referências literárias livre de dicotomias. Não obstante, o passado da poesia moderna brasileira (incluindo aí os seus citados desdobramentos) era referência majoritária para grande parte de nossa produção literária entre as décadas de 1960 e 1990.

No início dos anos 2000, novas propostas surgiram, mesclando as referências nacionais às internacionais para criar vozes poéticas como as de Ricardo Domeneck e Angélica Freitas, apenas para citar alguns exemplos. Poetas com trânsito entre a academia e as publicações independentes, como Annita Costa Malufe e Marcos Siscar, também trouxeram, via exercício da tradução e da pesquisa teórica, múltiplas referências à poesia do presente. Não só os 
poetas contemporâneos, como também aqueles artistas do passado que ficaram ofuscados pelos grandes nomes foram revisitados com maior interesse. $\mathrm{O}$ universo que esses poetas brasileiros descortinavam orientou-os para uma prática cujos referentes advindos de países e de épocas distintas trouxeram uma constelação de estratégias e motivos como matéria de poesia.

Marília Garcia é um exemplo desse olhar que foge da dicotomia participação/estetização, que deu o tom do debate poético brasileiro majoritário em quase todo o século passado. Em sua escrita, encontramos a coloquialidade convivendo com os experimentos de linguagem, em camadas sobrepostas, delineando um discreto fio narrativo que perpassa os poemas do volume. Há um ritmo de composição do livro, para além de cada peça individual. São temas e termos que retornam, o que inspira Italo Moriconi - na orelha do livro - a mencionar que o método compositivo "é dado pelo loop [...], pela estereofonia, pela espiral".

Na sexta parte do poema apresentado como epílogo do livro, intitulado "estrelas descem à terra (do que falamos quando falamos de uma hélice)", há um detalhamento de determinada estratégia de composição que se baseia no recorte de notícias:

o poema "malaysia airlines voo MH17"

tinha sido escrito a partir de notícias

tiradas do site G1

assim recortei o texto do site/inseri quebras de verso

excluí informações

trocando algumas coisas de lugar

$[\ldots]$

seria possível deslocar as palavras

de modo a produzir alguma coisa

que eu não estava vendo?

diferente do que aparecia

no jornal? (Garcia, 2017, p. 82).

Seria ingênuo, como leitores, abraçarmos esses versos como uma explicação do próprio método compositivo de Marília Garcia, pois estaríamos, assim, incorrendo na confusão entre sujeito histórico e a voz literária da poeta. No entanto, essa formulação levanta uma reflexão a partir do próprio texto, que não podemos ignorar. Algumas estrofes após as transcritas anteriormente, encontramos os 
versos: "eu tentava reaprender a ver: recortar e colar selecionar/ uma palavra para colar em outro ponto / como numa ilha de edição". O que se busca apreender não é tanto o evento cotidiano quanto a forma como ele é apresentado. As notícias, a lataria do avião, o olhar do amante, a construção do poema (todos temas visitados) - quais são as suas engrenagens? Como operam sob a superfície plácida de coisas que se mostram como acabadas?

Não por acaso, há em "tem país na paisagem? (versão compacta)" a menção ao termo "infra-ordinário", cunhado pelo escritor Georges Perec e que deu nome a um de seus livros póstumos:

$\mathrm{O}$ que realmente acontece, o que vivemos, o resto, tudo o mais, onde está? O que acontece a cada dia e o que retorna a cada dia, o banal, o cotidiano, o óbvio, o comum, o ordinário, o infra-ordinário, o ruído de fundo, o habitual, como explicá-lo, como interrogá-lo, como descrevê-lo? (Perec, 2015, p. 11, tradução nossa).

A provocação lançada pelo autor francês volta-se contra o sequestro da rotina pela sociedade do espetáculo e das manchetes catastróficas, que parecem sempre desviar nossa atenção da progressão ordinária da vida. A indústria das notícias, por esse ponto de vista, deforma nossa percepção até que não sejamos mais capazes de reconhecer o que está a nossa volta. "Os trens começam a existir apenas quando são descarrilados, e quanto mais passageiros estiverem mortos, mais trens existem", escreve Perec (2015, p. 11, tradução nossa).

Em diálogo direto com essa proposta de buscar o que se esconde sob a aparência de banalidade em uma cena que se fixou na memória ou em um local geográfico visitado, os textos de Marília Garcia vão fazendo brotar incertezas, que atingem, inclusive, o próprio fazer poético:

eu tinha tentado usar

a frieza da linguagem jornalística

mas minha vontade era tentar ver

a dimensão trágica de tudo

seria possível deslocar o texto

de modo a produzir outro sentido para as coisas? (Garcia, 2017, p. 86)

É a engrenagem do poema que salta à vista do leitor enquanto este vai se apropriando dos textos e dos elementos composicionais que surgem e ressurgem ao longo das páginas de um livro que tem 
título tão sugestivo. As câmeras são como artefatos que substituem os olhos. Na sociedade informacional, quantos são os olhos que nos cercam e registram recortes da realidade sem cessar? E que fatiam o espaço, com a pretensão de captar a realidade, freneticamente?

Talvez a câmera lenta seja o poema, em sua tentativa de colocar esse movimento de frenética vigilância em slow motion. O poema trabalha para livrar os olhos-câmera de seu movimento automático, incessante, para conquistar uma dimensão em que a ação não está desconectada da contemplação, antes, contemplar é o motor do agir. Essa força vital e questionadora da linguagem poética é ponderada em uma bela passagem do filósofo Vilém Flusser: "nem sempre estamos cientes do que devemos à poesia, no sentido lato da palavra: quase tudo que percebemos e vivenciamos. Fazer poesia é a produção de modelos de experiência, e sem tais modelos não poderíamos perceber quase nada" (Flusser, 2001, p. 113).

É, portanto, daí que podemos retirar algumas conclusões sobre como o tema dos meios de transporte irá marcar a construção da voz lírica em Câmera lenta. No livro, aviões, helicópteros, trens, automóveis, caminhões passeiam por grande parte das composições, como nos poemas "é uma love story e é sobre um acidente", "tem país na paisagem (versão compacta)", "capítulo II, por intermédio do naturalista" e "estrelas descem à terra (do que falamos quando falamos de uma hélice)".

Esses recursos utilizados para o deslocamento veloz são tema frequente em parte da literatura pós-Revolução Industrial, ainda que não possamos nos esquecer de um exemplo dessa busca pela superação dos limites físicos humanos que já estava implícita no mito de Ícaro. Se a ambição de voar alto do filho de Dédalo pode ser compreendida como desejo de equiparar-se aos deuses, seu ato foi motivado pela tentativa de resolução de um problema: fugir do labirinto do Minotauro.

Especificamente no último trabalho de Marília Garcia, os meios de transporte mantêm o aspecto primordial de dispositivos para o deslocamento (a busca pela resolução de problema que motivou Ícaro a voar), mas carregam também o presságio de uma ameaça (ruídos ensurdecedores, perigo de acidente, ameaça de terrorismo). Pior do que isso, também podem impedir que seja ouvida a voz que, do poema, tenta projetar-se rumo a um interlocutor (ou ouvinte): 
talvez a gente pudesse fazer silêncio

e de repente neste silêncio

acontecer de ouvir algo por detrás

dos ruídos das máquinas voadoras que

cruzam o céu (Garcia, 2017, p. 12).

Esse sujeito lírico instável, que exalta o momento (e não a sua sublimação), singulariza o trabalho de Marília Garcia, em particular, nesse seu livro mais recente, cujo equilíbrio entre experimentação e excelência formal se destaca. Há a recuperação da preocupação de um acabamento estético de sua publicação inaugural, sem abandonar o percurso teórico-empírico dos volumes posteriores. Em Câmera lenta, a poeta dialoga com as referências internacionais anteriormente apontadas, mas também com a escrita não criativa de Kenneth Goldsmith (2011), na qual o autor opera como curador, colocando a informação que coleta do mundo em movimento, alterando seu sentido prévio para obter novas leituras. No âmbito da literatura nacional, o diálogo mais evidente é com a obra de Ana Cristina Cesar, mas podemos também pensar num eco distante da lírica bandeiriana, ainda que nesta o canto da vida cotidiana tivesse uma leveza interditada à poesia mais recente.

No presente, vivemos uma crise da noção de dimensão, na qual o espaço substancial (contínuo e homogêneo) torna-se menos importante do que o espaço acidental (descontínuo e heterogêneo). Assim, de acordo com o filósofo Paul Virilio (1993, p. 31), à estética da aparição de uma imagem estável (analógica), sucede-se uma estética do desaparecimento de uma imagem instável (digital). A velocidade com que oscilamos entre as realidades atual e virtual acarreta uma crise da representação em que as grandes narrativas perdem espaço para uma reunião de fragmentos. $O$ autor contemporâneo escreve para um leitor cuja percepção está constantemente dividida entre o que presencia e o que observa pela janela sempre luminosa de nossos dispositivos eletrônicos.

Essas reflexões nos permitem recuperar a afirmação que fizemos no início deste texto, sobre a possibilidade de comparar - por meio do tema dos meios de transporte - alguns trabalhos poéticos de fins do século XX com a obra de Marília Garcia, que demonstra claramente um desejo de resistir à desrealização do mundo. A voz lírica que se projeta em seus poemas monta e remonta discursos 
próprios e alheios, em repetições ou formulações inéditas, que não só duplicam imagens em Câmera lenta, como criam uma espécie de câmara de ecos, em que reverberam palavras, situações, recursos poéticos já utilizados com pequenas diferenças, como se essa persistência desafiasse a celeridade do mundo contemporâneo.

Nos poemas examinados por Viviana Bosi, ${ }^{3}$ à exceção do texto de Ana Cristina Cesar, temos a fixação de uma cena sobre a qual o sujeito lírico reflete, conseguindo, de certa forma, congelar uma cena de impacto para repercutir um breve instante. Já na obra de Marília Garcia, especialmente em seu mais recente livro, destaca-se a complexidade composicional e a quantidade de recursos heterogêneos utilizados para construir o poema: colagens, sobreposições, reiterações. Também, conforme já comentamos, os "cenários" e "personagens" dos poemas transcendem o âmbito local, para criar uma cartografia particular, em que a locomoção rápida contribui para uma carga temporal em detrimento do espaço. Mesmo que o poema tente reconstruir, pela memória, a dimensão espacial, os corpos físicos estão em iminência de se apartar ("você ainda vai me ver três vezes / antes do fim. Fique atenta / aos sinais") ou de se desfazer ("você entre as ferragens"; "os corpos caíram do céu"). E as hélices, os acidentes, o ruído das máquinas voadoras pressagiam a pergunta que está na terceira seção do último poema do livro e que deixaremos ressoando aqui: "nesse momento de superfícies abertas / como lidar com a impossibilidade / de sair do lugar?".

\section{Referências}

BOSI, Viviana (2010). Poesia auto-móvel. Teresa: Revista de Literatura Brasileira, São Paulo, n. 10-11, p. 121-141.

CATRÓPA, Andréa (2015). Quem fala nos textos críticos de Ana Cristina Cesar? In: FALEIROS, Álvaro; ZULAR, Roberto; BOSI, Viviana (Org.). Sereia de papel: Visões de Ana Cristina Cesar. Rio de Janeiro: Editora da UERJ.

\footnotetext{
${ }^{3}$ Os poemas são: "Momento", de José Paulo Paes; "Spiritus ubi vult spirat", de Sebastião Uchôa Leite e o texto que se inicia com os versos "Não, a poesia não pode esperar", de Ana Cristina Cesar. Conforme comentamos brevemente em nosso texto, há um diálogo da obra de Marília Garcia com a de Cesar, em que a composição esfacelada do poema é a que mais se aproxima dos recursos utilizados pela autora de Câmera Lenta.
} 
CESAR, Ana Cristina (2013). Poética. São Paulo: Companhia das Letras.

COMBE, Dominique (2010). A referência desdobrada: o sujeito lírico entre a ficção e a autobiografia. Revista USP, São Paulo, n.84, p. 112-128.

FLUSSER, Vilém (2017). A escrita: há futuro para a escrita? São Paulo: Annablume.

GARCIA, Marília (2006). 20 poemas para seu walkman. São Paulo: Cosac Naify; Rio de Janeiro: 7Letras.

GARCIA, Marília (2010). A topologia poética de Emmanuel Hocquard. 162 f. Tese (Doutorado em Estudos Literários) - Universidade Federal Fluminense, Niterói.

GARCIA, Marília (2016). Um teste de resistores. Rio de Janeiro: 7Letras.

GARCIA, Marília (2017). Câmera lenta. São Paulo: Companhia das Letras.

GOLDSMITH, Kenneth (2011). Uncreative writing: managing writing in the digital age. Nova York: Columbia University Press.

GORMLEY, Anthony (2007). Blind Light. Anthony Gormley. Site pessoal. Arquivo de exposição. On-line. Disponível em: < https://bit.ly/2wsTMQe>. Acesso em: 24 jun. 2014.

HOLLANDA, Heloísa Buarque de (1998). Esses poetas: uma antologia dos anos 90. Rio de Janeiro: Aeroplano.

MALPOIX, Jean-Michel (2001). La poésie, autobiographie d'une soif. JeanMichel Maulpoix $\mathcal{E}$ Cie. Blog pessoal. On-line. Disponível em: <https:/ / bit.ly/2PTdNrt>. Acesso em: 21 jun. 2018.

MILANEZE, Erica (2014). O lirismo crítico e a pós-poesia: diferentes propostas estéticas para a poesia contemporânea. Travessias Interativas, Sergipe, V. 8, n. 2. Disponível em: <https:/ / bit.ly/2C3hDvf>. Acesso em: 19 jun. 2018

PEREC, Georges (2015). L'infra-ordinaire. Paris: Le Seuil.

RABATÉ, Dominique (Org.) (2001). Figures du sujet lyrique. Paris: PUF.

RABATÉ, Dominique; SERMET, Joëlle de; VADÉ, Yves (Org.) (1996). Le sujet lyrique em question. Bordeaux: Presses Universitaires de Bordeaux. (Modernités, n. 8).

VIRILIO, Paul (1993). O espaço crítico. Tradução de Paulo Roberto Pires. São Paulo: 34 .

Recebido em 15 de setembro de 2017.

Aprovado em 3 de junho de 2018. 


\section{resumo/abstract/resumen}

\section{Marília Garcia: para onde nos levam as hélices do poema?}

Andréa Catrópa da Silva

Em 2017, a poeta brasileira Marília García publicou Câmera lenta, livro que se destaca pelo equilíbrio entre a continuidade das experimentações estéticas já iniciadas anteriormente e a resolução formal de cada poema. O mote dos meios de transporte, elo com outras poéticas da modernidade, ganha aqui tratamento particular e em consonância com outros questionamentos da contemporaneidade. Entre hélices, turbinas, voos e aeronaves que aparecem frequentemente nos seus versos emerge um sujeito lírico na iminência da desintegração, mas que insiste no poema como forma de ecoar a experiência única e ancorada no tempo que consiste na vida humana.

Palavras-chave: Marília Garcia, poesia brasileira contemporânea, poesia e modernidade, poesia literal, lirismo crítico.

\section{Marília Garcia: where do the poem's propellers lead us?}

Andréa Catrópa da Silva

In 2017, the Brazilian poet Marília García published Câmara lenta, a book in which we find a remarkable dialogue with her recent aesthetic experiments and the formal resolution of each poem. The theme of means of transportation, a link with other poetics of modernity, gains here a particular treatment and aligns with other contemporary questions. The propellers, turbines, flights, and aircraft that frequently appear in her verses share space with a lyrical subject at the threshold of disintegration, but who insists on the poem as a way to echo the unique and anchored experience in the time that constitutes human life.

Keywords: Marília Garcia, contemporary Brazilian poetry, poetry and modernity, literal poetry, critical lyricism.

\section{Marília Garcia: ¿a dónde nos llevan las hélices del poema?}

Andréa Catrópa da Silva

En 2017, la poeta brasileña Marília García publicó Câmera lenta, un libro que se destaca por el equilibrio entre la continuidad de las experimentaciones estéticas ya iniciadas anteriormente y la resolución formal de cada poema. El tema de los medios de transporte, que es un punto de contacto con otras poéticas de la modernidad, gana aquí tratamiento particular y en 
consonancia con otros cuestionamientos de la contemporaneidad. Entre hélices, turbinas, vuelos y aeronaves que aparecen frecuentemente en sus versos emerge un sujeto lírico en la inminencia de la desintegración, pero que insiste en el poema como forma de dar eco a la experiencia única y anclada en el tiempo en que consiste la vida humana.

Palabras clave: Marília Garcia, poesía contemporánea brasileña, poesía y modernidad, poesía literal, lirismo crítico. 